\title{
Antiphospholipase A2 Receptor Autoantibodies: A Step Forward in the Management of Primary Membranous Nephropathy
}

\author{
Bogdan Obrisca, ${ }^{1}$ Gener Ismail, ${ }^{1,2}$ Roxana Jurubita, ${ }^{1,2}$ Catalin Baston, ${ }^{1,3}$ \\ Andreea Andronesi, ${ }^{1,2}$ and Gabriel Mircescu ${ }^{1,4}$ \\ 1 "Carol Davila” University of Medicine and Pharmacy, Dionisie Lupu Street No. 37, District 1, 022328 Bucharest, Romania \\ ${ }^{2}$ Center of Internal Medicine-Nephrology, Fundeni Clinical Institute, 258 Fundeni Street, District 2, 022328 Bucharest, Romania \\ ${ }^{3}$ Center for Uronephrology and Renal Transplantation, Fundeni Clinical Institute, 258 Fundeni Street, District 2, \\ 022328 Bucharest, Romania \\ 4 "Dr. Carol Davila” Teaching Hospital of Nephrology, Calea Grivitei Street No. 4, District 1, 010731 Bucharest, Romania
}

Correspondence should be addressed to Gener Ismail; gener732000@yahoo.com

Received 2 June 2015; Revised 19 September 2015; Accepted 30 September 2015

Academic Editor: Jennifer Pluznick

Copyright (C) 2015 Bogdan Obrisca et al. This is an open access article distributed under the Creative Commons Attribution License, which permits unrestricted use, distribution, and reproduction in any medium, provided the original work is properly cited.

\begin{abstract}
Since the identification of PLA2R (M-type phospholipase A2 receptor) as the first human antigenic target in primary membranous nephropathy $(\mathrm{MN})$, perpetual progress has been made in understanding the pathogenesis of this disease. Accumulating clinical data support a pathogenic role for the anti-PLA2R antibodies (PLA2R ABs), but confirmation in an animal model is still lacking. However, PLA2R ABs were related to disease activity and outcome, as well as to response therapy. Accordingly, PLA2R ABs assay seems to be promising tool not only to diagnose $\mathrm{MN}$ but also to predict the course of the disease and could open the way to personalize therapy. Nevertheless, validation of a universal assay with high precision and definition of cut-off levels, followed by larger studies with a prolonged follow-up period, are needed to confirm these prospects.
\end{abstract}

\section{Introduction}

Despite the increasing prevalence of the focal and segmental glomerulosclerosis in certain subpopulations [1-5], primary membranous nephropathy (MN) is still the leading cause of adult nephrotic syndrome in the Caucasian populations [6-8]. Primary membranous nephropathy is a glomerulusspecific autoimmune disorder in which subepithelial in situ formation of immune complexes injures the glomerulus [9].

The landmark papers identifying the M-type phospholipase A2 receptor (PLA2R) [10] and the Thrombospondin Type-1 Domain Containing-7A (THSD7A) [11] as human antigenic targets in adult $\mathrm{MN}$ in $70-75 \%$ and, respectively, $2.5-5 \%$ of cases restricted the designation of "idiopathic" disease to a minority of cases.

\section{PLA2R AB and MN Pathogenesis}

PLA2R is a type I transmembrane glycoprotein, member of the mannose receptor (MR) family. Characteristically, all four members of the MR family have a large extracellular glycosylated region comprising an $\mathrm{N}$-terminal cysteine-rich domain (CysR), a fibronectin-like type II domain (FnII), and eight to ten C-type lectin-like domains $\left(\mathrm{CTLD}_{1-10}\right)$ [12-14]. PLA2R serves primarily as a receptor for secretory PLA2, allowing its removal from circulation, thus regulating its biological effect [15-17].

As in many other autoimmune diseases, the triggering event of anti-PLAR2 and anti-THSD7A autoantibodies formation is still a matter of debate. Beck et al. [10] observed that anti-PLA2R antibodies recognize their target antigen only under nonreducing conditions suggesting that PLA2R contains a conformation-dependent epitope. Kao et al. [18] were the first to describe the location of the immunodominant epitope within PLA2R. They observed that a threedomain protein complex-consisting of CysR, FnII, and CTLD1-is recognized by sera from patients with MN. In addition, absence of either CysR or CTLD1 domain rendered the remaining fragments without any antigenicity, thereby supporting the critical importance of these two domains. 
It appears that CTLD1 is essential for stabilizing the structure of this epitope given the presence of a disulfide bond between CTLD1 and FnII which explains, at least in part, the sensitivity to reducing conditions.

Later on, Fresquet et al. [19] described eight peptides, located in the CysR, FnII, CTLD3, and interdomain loops between CTLD 1/2 and CTLD 2/3, as potential constituents of the PLA2R major epitope. These peptides are discontinuously spread in the primary structure of the protein but are brought in proximity through disulfide bonds in the tertiary structure, forming the three-dimensional configuration characteristic of the epitope. A more careful analysis revealed that only two of these peptides, located in a close region in CysR, possess the ability to successfully bind to anti-PLA2R antibodies, thereby defining the major epitope in PLA2R.

However, it is still unknown what sets up the immunogenicity of this antigen. A complex interplay of genetic and probably environmental factors could be the pathogenic trigger for $\mathrm{MN}$. Genetic variants within the coding region of the PLA2R gene on chromosome 2 strongly associated with the development of MN were identified by genomewide analyses. However, these single nucleotide polymorphisms are also frequently found in the general population, contrasting with the rarity of this disease [20, 21]. The intervention of environmental factors, not yet identified, could induce structural changes of PLA2R or expression of its hidden epitopes, making it antigenic [22]. The combined intervention of these factors could lead to the expression of PLA2R with a specific amino acid sequence, allowing for a particular three-dimensional conformation capable of activating the innate immune system.

The dendritic cells will intercept the modified epitopes of PLA2R and will then present them in association with the HLA protein to the cells of adaptive immune system [22]. Single nucleotide polymorphisms of HLA-DQA1 genes on chromosome 6 were also associated with MN [23] and it was suggested that the modified antigen presenting protein HLADQA1 could be involved in the initiation of an autoimmune response targeting variants of PLA2R1 [22]. In addition, molecular mimicry could play a role, as peptides of PLA2R showed partial homology with bacterial cell wall enzyme common to Clostridium species [24, 25].

The main characteristic of immune response in $\mathrm{MN}$ is the predominant activation of Th2 lymphocytes, which in turn will produce certain cytokines, especially IL-4, IL-10, and IL13 [26-28]. IL-4 will subsequently activate the B-lymphocytes to synthetize IgG4, the main immunoglobulin subclass found in $\mathrm{MN}[10,29]$. IgG4 will bind to the conformational epitope of PLA2R1 located on the podocyte surface, forming the characteristic subepithelial immune complexes (Figure 1).

Although the current evidence of the role of anti-PLA2R antibodies in the pathogenesis of MN has enlightened our understanding of the disease, a transgenic animal model of $\mathrm{MN}$ is still needed for a direct proof of a pathogenic link between PLA2R ABs and MN. This approach could offer some answers regarding which subtype of immunoglobulin or complement pathway is majorly involved in this disease, which is the actual trigger of this autoimmune process, and why the clinical manifestations are limited to the kidney,

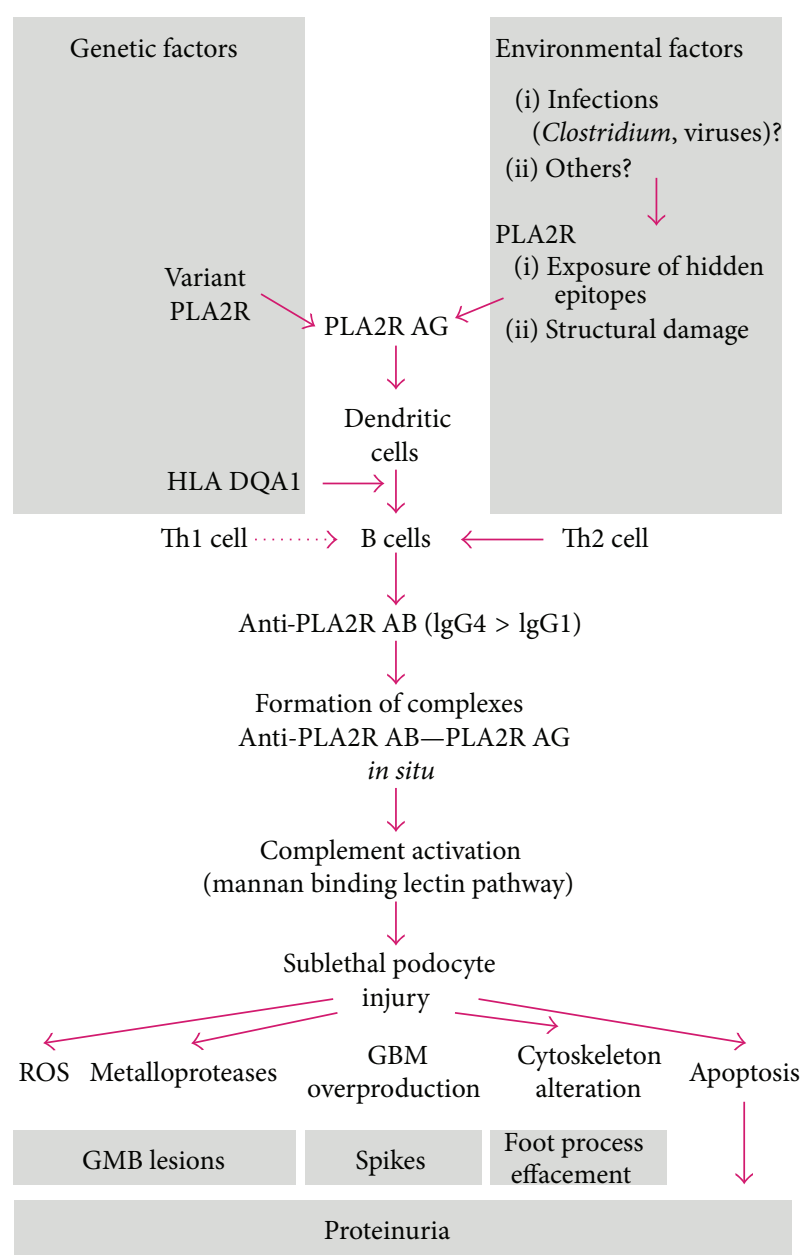

FIgure 1: Phospholipase A2 receptor (PLA2R), anti-PLA2R antibody (anti-PLA2R AB), and membranous nephropathy pathogenesis. GBM: glomerular basement membrane; ROS: reactive oxigen species.

although PLA2R is also expressed on alveolar type II epithelial cells and on leukocyte surface $[10,18]$.

The formation of immune complexes and their accumulation in electron-dense deposits disrupt the functional integrity of the glomerular filtration barrier by a complement-dependent process. However, IgG4 does not activate the complement. As mannose-binding lectin (MBL) was identified in the glomeruli of patients with MN [30] but Clq (a marker of activation by the classical pathway) was not, it was hypothesized that the MBL pathway of complement activation is mainly implicated. Mannose-binding lectin is a member of the collectin family of proteins and, in the presence of calcium, has high affinity for certain oligosaccharides such as $\mathrm{N}$-acetyl glucosamine, mannose, and fucose residues [31]. Another suggestion that immune complexes activate the complement system via MBL pathway comes from the observation that IgG4 anti-PLA2R antibodies have galactosedeficient side chains. Because the galactose molecules are fewer, the $\mathrm{N}$-acetyl glucosamine could be exposed in the terminal position and interact and activate MBL. MBL will 
then activate two serine proteases (MASP 1/2, MBL associated serine protease), which act similarly to $\mathrm{Clr}$ and $\mathrm{Cls}$ by splitting C4 (into C4a and C4b) and C2 (into C2a and C2b). $\mathrm{C} 4 \mathrm{~b}$ and $\mathrm{C} 2 \mathrm{a}$ bind together to form C3-convertase, as in the classical pathway, ultimately resulting in the formation of the membrane attack complex (MAC) [31].

However, not all cases of MN seem to share the activation of complement by the MBL pathway. Debiec et al. [32] have described a remarkable case of recurrent $\mathrm{MN}$ in an allograft, 13 days after renal transplantation. The graft biopsy specimen showed typical granular staining for C3, C5bC9, Clq, and IgG3 $\kappa$ (with $\kappa$ light chains) and not MBL or IgG4, as would have been expected. A retrospective analysis of the biopsy from the native kidney revealed the same pattern. The presence of monoclonal anti-PLA2R antibodies of IgG3 $\kappa$ subclass (which has the highest Clq binding ability) in both native and graft biopsy specimens, together with $\mathrm{Clq} / \mathrm{C} 3 / \mathrm{C} 5 \mathrm{~b}-9$ deposits, suggests that, at least in this particular case, the classical complement pathway is majorly involved, contrasting with most common forms of $\mathrm{MN}$, in which IgG4 and MBL are the main actors.

After its insertion into cell membranes, MAC is taken up by podocytes, transported intracellularly, and then eliminated in the urinary space $[33,34]$. The repair of the cell membrane occurs rather rapidly. Thus, unlike in other situations, in $\mathrm{MN}, \mathrm{MAC}$ is assembled in sublytic quantities and activates the podocyte rather than destroying it, leading to a series of maladaptative reactions [35]. Overproduction of ROS (reactive oxygen species) by upregulation of NADPH-oxidase will eventually contribute to the alteration of glomerular basement membrane (GBM) as will the synthesis of certain metalloproteases, which disrupt the GBM [36]. Overproduction of extracellular matrix components (type IV collagen, laminin, heparin sulfate, and fibronectin) will thicken the basement membrane and will be deposited around the immune complexes as spike-like extensions. Condensation of actin microfilaments alters the podocyte's cytoskeleton with subsequent effacement of foot processes. Moreover, actin will dissociate from nephrin (the key component of the slit diaphragm), altering the functional integrity of the glomerular filtration barrier. Finally, the apoptosis of podocytes will be favored. All these changes alter the glomerular filtration barrier and result in heavy proteinuria, the main clinical manifestation of MN (Figure 1).

\section{Could PLA2R ABs Assay Allow Avoiding Biopsy?}

Several studies over the past years translated anti-PLA2R antibodies from research laboratories to bedside, by evaluating their diagnostic and prognostic and monitoring potential utilities. Once PLA2R was identified as the major target antigen in $\mathrm{MN}$, the corresponding antibody was regarded as a putative serologic biomarker of the disease. Indeed, patients with active $\mathrm{MN}$ were anti-PLA2R positive in $52 \%$ and $82 \%$ of cases $[10,37-47]$. Thus, the specificity seems to be high, around $70-80 \%$, but not $100 \%$, and had variations dependent probably on the assay (Western Blot, indirect immunofluorescence, or ELISA) and of the population cases [10, 37-47] (Table 1). More recently, commercial kits for PLA2R ABs ELISA assay in serum, with excellent concordance with indirect immunofluorescence test, became available [38]. However, although the current immunoassays seem able to detect all PLA2R ABs, the recently described immunodominant epitope within PLA2R could offer the possibility to develop more efficient tools for MN diagnosis $[18,19,24]$.

Apart from analytical variation, other factors could explain why specificity of PLA2R ABs is not $100 \%$. In fact, only a high PLA2R ABs titer indicates $\mathrm{MN}$ with a high probability, as a low titer test does not exclude $\mathrm{MN}$, since $20 \%$ to $30 \%$ of the patients with $\mathrm{MN}$ are negative for both anti-PLA2R and anti-THSD7A ABs, which appear to be mutually exclusive $[10,11]$, regardless of the assay used. Other antigens, undetected so far, could also play a role in the pathogenesis of MN. Several other antibodies directed against some intracellular podocyte proteins have been described, such as aldose reductase, superoxide dismutase, and $\alpha$ enolase. Murtas et al. [48] noticed high prevalence of these anti-cytoplasmic antibodies in the serum of patients with $\mathrm{MN}$, of which $10 \%$ were positive for all antibodies (including anti-PLA2R antibody) and $20 \%$ were negative for all. The coexistence of different circulating anti-podocyte antibodies suggests a complex pathogenesis, which involves several target antigens, some of them still undetected. However, the role of these anti-cytoplasmic antibodies, their translocation from the cytoplasm to the membrane surface, the mechanism of interaction with PLA2R, and their clinical significance are questions that need answers for a better understanding of the disease. Finally, in some cases, proteinuria could persist even after the immunological activity was lost [10], as supported by Svobodova et al. [44] study where $22 \%$ of MN patients were anti-PLA2R AB positive, while PLA2R AG was found in $59 \%$ of the corresponding biopsies.

On the other hand, in several cases, PLA2R ABs had been detected in the serum of some patients with presumably secondary MN, due to lupus, sarcoidosis, hepatitis B infection, and cancer [49-51]. The reported sensitivity varied between 80 and $100 \%[10,41,43]$. However, it is more likely that in such cases $\mathrm{MN}$ is coincidentally superimposed on other diseases. This assumption is sustained by the high prevalence of certain neoplasia (lung, colorectal, or gastric) occurring at the age of 40 to 50 years (similar to the onset age of $\mathrm{MN}$ ) and by the high prevalence of $\mathrm{HBV}$ infection in certain geographic regions [37].

Therefore, also an increased PLA2R ABs titer could indicate with a high probability an active $\mathrm{MN}$; the specificity and sensitivity are not high enough to avoid a kidney biopsy. However, PLA2R ABs assay opened a new perspective: at some point, serology will replace histopathology in the diagnosis of $\mathrm{MN}$.

\section{Could PLA2R ABs at Presentation Predict the Course of MN?}

Predicting the clinical course of a patient with $\mathrm{MN}$ at disease onset seems rather impossible because of its variable 
TABLE 1: Studies investigating the anti-PLA2R antibodies in primary membranous nephropathy.

\begin{tabular}{|c|c|c|c|}
\hline Author & Number of patients & Method & Results \\
\hline $\begin{array}{l}\text { Beck et al. [10] } \\
(2009)\end{array}$ & 26 & WB & $\begin{array}{l}\text { Anti-PLA2R ABs: } \\
\text { (i) Positive when there was clinically significant disease activity in } 70 \% \text { of } \\
\text { primary MN cases but in none of secondary MN cases ( } 100 \% \text { specificity) } \\
\text { (ii) Declined or disappeared in remission }\end{array}$ \\
\hline $\begin{array}{l}\text { Hofstra et al. [39] } \\
\text { (2011) }\end{array}$ & 18 & WB & $\begin{array}{l}\text { (i) } 78 \% \text { of MN patients were PLA2R ABs positive } \\
\text { (ii) PLA2R ABs levels correlated strongly with both clinical status and } \\
\text { proteinuria }\end{array}$ \\
\hline $\begin{array}{l}\text { Beck et al. [40] } \\
(2011)\end{array}$ & 35 & WB & $\begin{array}{l}\text { (i) } 71 \% \text { of MN patients were PLA2R AB positive } \\
\text { (ii) Complete and partial remissions were more frequent in patients on } \\
\text { rituximab who demonstrated decline or disappearance of PLA2R ABs ( } 59 \text { and } \\
88 \% \text { versus } 0 \text { and } 33 \% \text { ) } \\
\text { (iii) Rituximab-induced changes in antibody levels preceded changes in } \\
\text { proteinuria }\end{array}$ \\
\hline
\end{tabular}

\begin{tabular}{|c|c|c|c|}
\hline & $360(100$ primary & & \\
\hline Hoxha et al. [41] & $\begin{array}{l}360 \text { (100 primary } \\
\text { MN; } 17 \text { secondary } \\
\text { MN; } 90 \text { other GN; }\end{array}$ & IFA & (i) Positive PLA2R ABs had $52 \%$ sensitivity and $100 \%$ specificity to detect $\mathrm{MN}$ \\
\hline
\end{tabular}

\begin{tabular}{|c|c|c|c|}
\hline $\begin{array}{l}\text { Hofstra et al. [38] } \\
(2012)\end{array}$ & 117 & IFA and ELISA & $\begin{array}{l}\text { (i) } 72 \% / 74 \% \text { of } \mathrm{MN} \text { patients were anti-PLA2R ABs positive } \\
\text { (ii) Excellent concordance between IFA and ELISA } \\
\text { (iii) Correlation between baseline PLA2R ABs and proteinuria } \\
\text { (iv) Spontaneous remissions more frequent in patients with lower PLA2R AB } \\
\text { titer }(38 \% \text { versus } 4 \%)\end{array}$ \\
\hline $\begin{array}{l}\text { Svobodova et al. } \\
{[44](2013)}\end{array}$ & 84 & IFA & $\begin{array}{l}\text { Only } 22 \% \text { of patients in remission were PLA2R ABs positive while PLA2R AG } \\
\text { was found in } 59 \% \text { of the corresponding biopsies }\end{array}$ \\
\hline $\begin{array}{l}\text { Kanigicherla et al. } \\
\text { [42] (2013) }\end{array}$ & $40 / 30(90)$ & ELISA & $\begin{array}{l}\text { High PLA2R ABs levels }(170.8 \mathrm{mcg} / \mathrm{mL}) \text { are linked with the following: } \\
\text { (i) Active disease } \\
\text { (ii) Higher risk of decline in renal function }\end{array}$ \\
\hline $\begin{array}{l}\text { Oh et al. [43] } \\
(2013)\end{array}$ & $100 / 69$ & WB & $\begin{array}{l}\text { (i) } 80 \% \text { of nephrotic primary MN patients and } 20 \% \text { of patients with secondary } \\
\text { MN were PLA2R ABs positive } \\
\text { (ii) PLA2R ABs titer at biopsy was related to MN activity but not to outcome }\end{array}$ \\
\hline $\begin{array}{l}\text { Bech Anneke et } \\
\text { al. [45] (2014) }\end{array}$ & 48 & ELISA & $\begin{array}{l}\text { (i) PLA2R ABs decreased after two months under immunosuppressive } \\
\text { therapy ( } 428 \mathrm{U} / \mathrm{mL} \text { to } 24 \mathrm{U} / \mathrm{mL} \text { ) } \\
\text { (ii) PLA2R ABs levels after } 2 \text { months of immunosuppressive therapy not at } \\
\text { baseline predicted long-term outcome: } 58 \% \text { and } 9 \% \text { of negative and positive } \\
\text { PLA2R ABs were in remission after } 5 \text { years }\end{array}$ \\
\hline $\begin{array}{l}\text { Hoxha et al. [46] } \\
\text { (2014) }\end{array}$ & 133 & IFA and ELISA & $\begin{array}{l}\text { (i) } 82 \% \text { of MN patients were PLA2R ABs positive } \\
\text { (ii) Patients experiencing remission had lower PLA2R ABs titers ( } 23 \text { versus } \\
54 \mathrm{mcg} / \mathrm{mL} \text { ) and IgG4 at baseline } \\
\text { (iii) PLA2R ABs declined faster than proteinuria ( } 81 \% \text { versus } 39 \% \text { after } 3 \\
\text { months) } \\
\text { (iv) PLA2R ABs titer at baseline was an independent risk factor for not } \\
\text { achieving remission of proteinuria }\end{array}$ \\
\hline $\begin{array}{l}\text { Segarra-Medrano } \\
\text { et al. [47] (2014) }\end{array}$ & 36 & & $\begin{array}{l}\text { (i) PLA2R ABs titer was significantly greater in patients with remission and it } \\
\text { preceded the clinical response } \\
\text { (ii) No association was observed between the antibody titer prior to treatment } \\
\text { and the mean response time or the response at } 12 \text { months } \\
\text { (iii) Reduction in PLA2R ABs titre is significantly associated with the time } \\
\text { until signs of remission }\end{array}$ \\
\hline
\end{tabular}

natural history. Classically, the natural history of $\mathrm{MN}$ is described by the "rule of thirds" according to which onethird of cases will remit spontaneously, another third will exhibit variable degrees of persistent proteinuria without deterioration in renal function, and the last third comprises the patients who progress to ESRD (end-stage renal disease) [52]. However, it could take from several months to 5 years to achieve a complete (urinary protein excretion $<0.3 \mathrm{~g} / \mathrm{d}$ ) or partial remission (urinary protein excretion $<3.5 \mathrm{~g} / \mathrm{d}$ and more than $50 \%$ reduction from peak values, accompanied by stable serum creatinine). In this regard, McQuarrie et al. [53] observed that approximately $75 \%$ of patients with MN can expect to achieve at least one partial remission (either spontaneous or treatment-induced) within 5 years 
from diagnosis, contrasting with the traditionally accepted "rule of thirds."

On the other hand, as immunosuppressive therapy is efficient but not without adverse effects, it should be reserved only to high-risk patients. Serial measurements of proteinuria and serum creatinine are currently used to identify highrisk patients, to predict outcome, and to guide therapy [54]. Various nomograms based on these parameters were designed [55], but more accurate prognostic markers are clearly needed.

The measurements of anti-PLA2R ABs could mark the beginning of the personalized medical management of $\mathrm{MN}$ patients, allowing abandoning the empirical approach used so far. The support for this concept comes from several studies, which have tried to evaluate the relation between antibody titers, the disease activity, and the response to therapy.

Several studies confirmed the relationship between PLA2R ABs and indices of MN activity (proteinuria, serum albumin level) first observed by Beck et al. (Table 1) [10, 38, $39,42,43]$. Hofstra et al. [39, 56] reported a strong correlation between anti-PLA2R AB titers and disease activity, as defined by proteinuria, not only at presentation but also during the follow-up period. They observed that antibody levels were high during the nephrotic phase of the disease, decreased in case of a spontaneous or treatment-induced remission, and increased again at disease recurrence. In addition, the observations that anti-PLA2R antibody levels positively correlated with other markers of kidney injury, such as urinary $\beta 2$-microglobulin, urinary IgG, and serum creatinine, further support the relationship between anti-PLA2R AB titer and disease activity.

More importantly, these authors observed that the antibody titer could predict the clinical outcome, as those with high antibody levels were less likely to achieve a spontaneous remission (4 versus 38\%). In another report, patients with higher PLA2R ABs were less likely to have a remission (spontaneous or therapy-induced) and antibody titer, not proteinuria, was an independent risk factor for not achieving remission [46]. Hence, as patients with high PLA2R ABs titer at presentation could have a more active disease and less chances of spontaneous remission, they could benefit from an earlier started immunosuppressive regimen.

\section{Could PLA2R ABs Guide the Therapy?}

In their landmark article, Beck et al. described a temporal relationship between PLA2R ABs and MN activity: the decrease in antibody titers preceded the decline in proteinuria, both in spontaneous and in therapeutic remissions [10]. They considered the observed relation in line with the observations made in the passive Heymann model of nephritis, where proteinuria persisted after the decline in antibody titer, also supporting a pathogenic role for PLA2R ABs: the immunological phase of MN must end before a clinical response is to be seen.

The delayed clinical response could be due to the time needed to operate several processes, for example, clearance

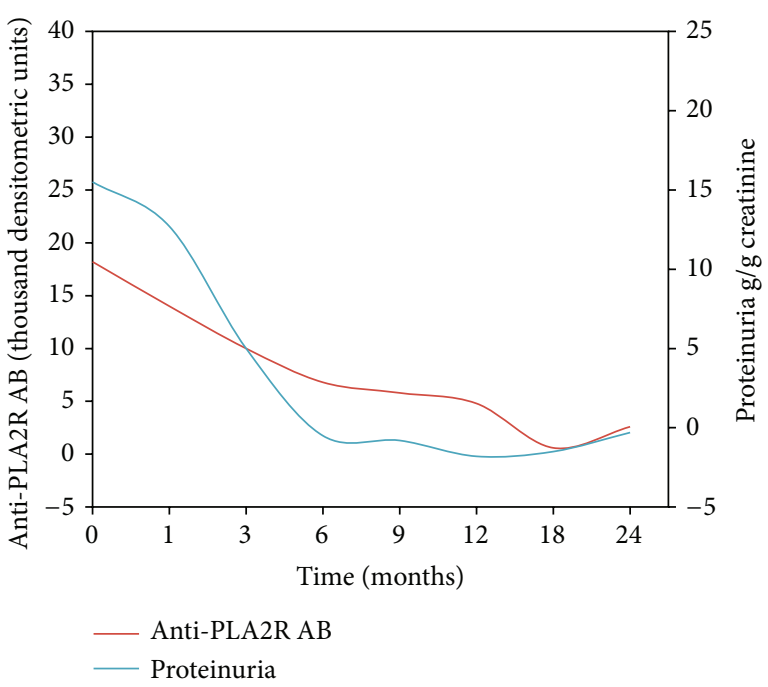

FIGURE 2: Anti-PLA2R AB and proteinuria in patients with primary membranous nephropathy after rituximab administration (data from Beck et al. [40]).

of immune complexes, recovery of the podocytes, and repair of slit diaphragm structural damage, which are essential to restore the functional integrity of the glomerular basement membrane.

Two other studies $[40,46]$ detailed the temporal relationship between the decline in anti-PLA2R antibody titer and proteinuria. In one, the changes in anti-PLA2R ABs levels always preceded the corresponding changes of proteinuria: the decline in antibody titer began rapidly after the start of immunosuppressive therapy, while the corresponding decline in proteinuria occurred slowly and gradually over the following 12-24 months (Figure 2). In the other, the PLA2R $\mathrm{ABs}$ titer fell by $81 \%$ three months after the initiation of immunosuppressive therapy and remained low thereafter, while proteinuria decreased by only $39 \%$ in the first three months but continued to decline slowly in the next 24 months [46]. Therefore, a decline in anti-PLAR2 AB could indicate a forthcoming remission.

Current guidelines recommend monitoring the response to therapy using proteinuria and kidney function (serum creatinine), parameters which describe the consequences of the immunological process. By measuring anti-PLA2R antibody titer, information on the immunological activity of the disease can be obtained and used to monitor the course of $\mathrm{MN}$ under therapy.

In this regard, Beck et al. [40] have evaluated the longterm outcome of 35 patients after treatment with rituximab. They observed that $59 \%$ and $88 \%$ of those with undetectable antibody after 12 months of therapy were in complete or partial remission at 12 and 24 months, respectively, as compared to $0 \%$ and $33 \%$ among those with persistent antibody. Similarly, Bech et al. [45] observed that antibody levels at the completion of immunosuppressive therapy predicted the long-term outcome: $58 \%$ of those with undetectable antibodies at the end of treatment were in persistent remission after 5 years, as compared to none of those with persistent 
antibodies. Thus, PLA2R-ABs measurements seem to be useful in evaluating the response to therapy and to predict long-term outcome in MN patients.

\section{How Can PLA2R AB Be Used to Personalize the Management of Primary Membranous Nephropathy Therapy?}

First, a low PLA2R ABs titer suggests a less immunologically active disease and could support the decision to delay the initiation of the immunosuppressive therapy [5760]. Second, in patients with high PLA2R ABs titer, the immunosuppressive therapy seems to be indicated even if proteinuria is lower than $8-9 \mathrm{~g} /$ day and before decline in kidney function. Third, the persistence of high antibody titer after several months of therapy should indicate that a switch to a different treatment protocol might be more appropriate. Finally, patients with proteinuria unresponsive to treatment but persistent undetectable serum antibodies are most likely to have an immunologically inactive disease. In these cases, focal segmental glomerulosclerosis secondary to the prolonged disease and tubule-interstitial damage could explain the residual proteinuria and make the immunosuppressive therapy unnecessary. Although these assertions are appealing, one should bear in mind that cut-off values for PLA2R ABs titers are still to be defined and controlled studies should validate these approaches [61].

In conclusion, measurement of anti-PLA2R antibodies is a useful tool for primary MN diagnosis and-in conjunction with other antibodies, still to be defined-would eventually eliminate the need of a kidney biopsy. Anti-PLA2R titers also could guide the therapy as they are related both to immunologic activity and to outcome. Obviously, implementing antiPLA2R measurements into clinical practice looks promising, but validation of a universal assay with high precision for anti-PLA2R detection and defining cut-off levels are needed. Furthermore, these preliminary data should be strengthened by additional, larger studies with an adequate follow-up period.

\section{Conflict of Interests}

The authors declare that there is no conflict of interests regarding the publication of this paper.

\section{References}

[1] G. L. Braden, J. G. Mulhern, M. H. O'Shea, S. V. Nash, A. A. Ucci Jr., and M. J. Germain, "Changing incidence of glomerular diseases in adults," American Journal of Kidney Diseases, vol. 35, no. 5, pp. 878-883, 2000.

[2] S. Swaminathan, N. Leung, D. J. Lager et al., "Changing incidence of glomerular disease in Olmsted County, Minnesota: a 30-year renal biopsy study," Clinical journal of the American Society of Nephrology, vol. 1, no. 3, pp. 483-487, 2006.

[3] M. Bahiense-Oliveira, L. B. Saldanha, E. L. Andrade Mota, D. Oliveira Penna, R. Toledo Barros, and J. E. Romão-Junior,
"Primary glomerular diseases in Brazil (1979-1999): is the frequency of focal and segmental glomerulosclerosis increasing?" Clinical Nephrology, vol. 61, no. 2, pp. 90-97, 2004.

[4] D. Dragovic, J. L. Rosenstock, S. J. Wahl, G. Panagopoulos, M. V. DeVita, and M. F. Michelis, "Increasing incidence of focal segmental glomerulosclerosis and an examination of demographic patterns," Clinical Nephrology, vol. 63, no. 1, pp. $1-7,2005$

[5] M. Haas, S. M. Meehan, T. G. Karrison, and B. H. Spargo, "Changing etiologies of unexplained adult nephrotic syndrome: a comparison of renal biopsy findings from 1976-1979 and 1995-1997," American Journal of Kidney Diseases, vol. 30, no. 5, pp. 621-631, 1997.

[6] S. R. Orth and E. Ritz, "The nephrotic syndrome," The New England Journal of Medicine, vol. 338, no. 17, pp. 1202-1211, 1998.

[7] S. M. Korbet, R. M. Genchi, R. Z. Borok, and M. M. Schwartz, "The racial prevalence of glomerular lesions in nephrotic adults," American Journal of Kidney Diseases, vol. 27, no. 5, pp. 647-651, 1996.

[8] F. Rivera, J. M. López-Gómez, and R. Pérez-García, "Clinicopathologic correlations of renal pathology in Spain," Kidney International, vol. 66, no. 3, pp. 898-904, 2004.

[9] H. A. Austin III, T. T. Antonovych, K. MacKay, D. T. Boumpas, and J. E. Balow, "Membranous nephropathy," Annals of Internal Medicine, vol. 116, no. 8, pp. 672-682, 1992.

[10] L. H. Beck Jr., R. G. B. Bonegio, G. Lambeau et al., "M-type phospholipase A2 receptor as target antigen in idiopathic membranous nephropathy," The New England Journal of Medicine, vol. 361, no. 1, pp. 11-21, 2009.

[11] N. M. Tomas, L. H. Beck, C. Meyer-Schwesinger et al., “Thrombospondin type-1 domain-containing 7A in idiopathic membranous nephropathy," The New England Journal of Medicine, vol. 371, no. 24, pp. 2277-2287, 2014.

[12] L. East and C. M. Isacke, "The mannose receptor family", Biochimica et Biophysica Acta: General Subjects, vol. 1572, no. 2-3, pp. 364-386, 2002.

[13] O. Llorca, "Extended and bent conformations of the mannose receptor family," Cellular and Molecular Life Sciences, vol. 65, no. 9, pp. 1302-1310, 2008.

[14] J. Boskovic, J. N. Arnold, R. Stilion et al., "Structural model for the mannose receptor family uncovered by electron microscopy of Endo180 and the mannose receptor," The Journal of Biological Chemistry, vol. 281, no. 13, pp. 8780-8787, 2006.

[15] K. Hanasaki and H. Arita, "Phospholipase $A_{2}$ receptor: a regulator of biological functions of secretory phospholipase $A_{2}$," Prostaglandins and Other Lipid Mediators, vol. 68-69, pp. 71-82, 2002.

[16] E. Zvaritch, G. Lambeau, and M. Lazdunski, "Endocytic properties of the M-type 180-kDa receptor for secretory phospholipases $\mathrm{A}_{2}$," The Journal of Biological Chemistry, vol. 271, no. 1, pp. 250-257, 1996.

[17] G. Lambeau, P. Ancian, J.-P. Nicolas et al., "Structural elements of secretory phospholipases A2 involved in the binding to Mtype receptors," The Journal of Biological Chemistry, vol. 270, no. 10, pp. 5534-5540, 1995.

[18] L. Kao, V. Lam, M. Waldman, R. J. Glassock, and Q. Zhu, "Identification of the immunodominant epitope region in phospholipase A2 receptor-mediating autoantibody binding in idiopathic membranous nephropathy," Journal of the American Society of Nephrology, vol. 26, no. 2, pp. 291-301, 2015. 
[19] M. Fresquet, T. A. Jowitt, J. Gummadova et al., "Identification of a major epitope recognized by PLA2R autoantibodies in primary membranous nephropathy," Journal of the American Society of Nephrology, vol. 26, no. 2, pp. 302-313, 2015.

[20] M. J. H. Coenen, J. M. Hofstra, H. Debiec et al., "Phospholipase A2 receptor (PLA2R1) sequence variants in idiopathic membranous nephropathy," Journal of the American Society of Nephrology, vol. 24, no. 4, pp. 677-683, 2013.

[21] P. Ancian, G. Lambeau, M.-G. Mattéi, and M. Lazdunski, "The human $180-\mathrm{kDa}$ receptor for secretory phospholipases A2. Molecular cloning, identification of a secreted soluble form, expression, and chromosomal localization," The Journal of Biological Chemistry, vol. 270, no. 15, pp. 8963-8970, 1995.

[22] C. Ponticelli and R. J. Glassock, "Glomerular diseases: membranous nephropathy-a modern view," Clinical Journal of the American Society of Nephrology, vol. 9, no. 3, pp. 609-616, 2014.

[23] J. Lv, W. Hou, X. Zhou et al., "Interaction between PLA2R1 and HLA-DQA1 variants associates with anti-PLA2R antibodies and membranous nephropathy," Journal of the American Society of Nephrology, vol. 24, no. 8, pp. 1323-1329, 2013.

[24] L. H. Beck, "The dominant humoral epitope in phospholipase A2 receptor-1: presentation matters when serving up a slice of $\pi$," Journal of the American Society of Nephrology, vol. 26, pp. 237-239, 2014.

[25] H. C. Stanescu, M. Arcos-Burgos, A. Medlar et al., "Risk HLA-DQA1 and PLA ${ }_{2} \mathrm{R} 1$ alleles in idiopathic membranous nephropathy," The New England Journal of Medicine, vol. 364, no. 7, pp. 616-626, 2011.

[26] A. Kuroki, M. Iyoda, T. Shibata, and T. Sugisaki, “Th2 cytokines increase and stimulate B cells to produce IgG4 in idiopathic membranous nephropathy," Kidney International, vol. 68, no. 1, pp. 302-310, 2005.

[27] K. Hirayama, I. Ebihara, S. Yamamoto et al., "Predominance of type- 2 immune response in idiopathic membranous nephropathy: cytoplasmic cytokine analysis," Nephron, vol. 91, no. 2, pp. 255-261, 2002.

[28] P. G. Tipping and A. R. Kitching, "Glomerulonephritis, Th1 and Th2: what's new?" Clinical and Experimental Immunology, vol. 142, no. 2, pp. 207-215, 2005.

[29] H. Imai, K. Hamai, A. Komatsuda, H. Ohtani, and A. B. Miura, "IgG subclasses in patients with membranoproliferative glomerulonephritis, membranous nephropathy, and lupus nephritis," Kidney International, vol. 51, no. 1, pp. 270-276, 1997.

[30] K. Lhotta, R. Würzner, and P. König, "Glomerular deposition of mannose-binding lectin in human glomerulonephritis," Nephrology Dialysis Transplantation, vol. 14, no. 4, pp. 881-886, 1999.

[31] A. Roos, M. R. Daha, J. van Pelt, and S. P. Berger, "Mannosebinding lectin and the kidney," Nephrology Dialysis Transplantation, vol. 22, no. 12, pp. 3370-3377, 2007.

[32] H. Debiec, M. Hanoy, A. Francois et al., "Recurrent membranous nephropathy in an allograft caused by IgG3 $\kappa$ targeting the PLA2 receptor," Journal of the American Society of Nephrology, vol. 23, no. 12, pp. 1949-1954, 2012.

[33] M. Schulze, J. V. Donadio Jr., C. J. Pruchno et al., "Elevated urinary excretion of the C5b-9 complex in membranous nephropathy," Kidney International, vol. 40, no. 3, pp. 533-538, 1991.

[34] S. P. Kon, B. Coupes, C. D. Short et al., "Urinary C5b-9 excretion and clinical course in idiopathic human membranous nephropathy," Kidney International, vol. 48, no. 6, pp. 1953-1958, 1995.

[35] A. V. Cybulsky, R. J. Quigg, and D. J. Salant, "Experimental membranous nephropathy redux," American Journal of Physiology: Renal Physiology, vol. 289, no. 4, pp. F660-F671, 2005.

[36] T. Takano, H. Elimam, and A. V. Cybulsky, "Complementmediated cellular injury," Seminars in Nephrology, vol. 33, no. 6, pp. 586-601, 2013.

[37] S. A. Timmermans, P. van Paassen, and J. W. Cohen Tervaert, "Recent advances in the understanding of immune-mediated nephrotic syndrome: diagnostic and prognostic implications," Expert Review of Clinical Immunology, vol. 11, no. 4, pp. 489500, 2015.

[38] J. M. Hofstra, H. Debiec, C. D. Short et al., "Antiphospholipase $A_{2}$ receptor antibody titer and subclass in idiopathic membranous nephropathy," Journal of the American Society of Nephrology, vol. 23, no. 10, pp. 1735-1743, 2012.

[39] J. M. Hofstra, L. H. Beck Jr., D. M. Beck, J. F. Wetzels, and D. J. Salant, "Anti-phospholipase $\mathrm{A}_{2}$ receptor antibodies correlate with clinical status in idiopathic membranous nephropathy," Clinical Journal of the American Society of Nephrology, vol. 6, no. 6, pp. 1286-1291, 2011.

[40] L. H. Beck Jr., F. C. Fervenza, D. M. Beck et al., "Rituximabinduced depletion of anti-PLA2R autoantibodies predicts response in membranous nephropathy," Journal of the American Society of Nephrology, vol. 22, no. 8, pp. 1543-1550, 2011.

[41] E. Hoxha, S. Harendza, G. Zahner et al., "An immunofluorescence test for phospholipase- $\mathrm{A}_{2}$-receptor antibodies and its clinical usefulness in patients with membranous glomerulonephritis," Nephrology Dialysis Transplantation, vol. 26, no. 8, pp. 2526-2532, 2011.

[42] D. Kanigicherla, J. Gummadova, E. A. McKenzie et al., "AntiPLA2R antibodies measured by ELISA predict long-term outcome in a prevalent population of patients with idiopathic membranous nephropathy," Kidney International, vol. 83, no. 5, pp. 940-948, 2013.

[43] Y. J. Oh, S. H. Yang, D. K. Kim, S.-W. Kang, and Y. S. Kim, "Autoantibodies against phospholipase $\mathrm{A}_{2}$ receptor in Korean patients with membranous nephropathy," PLOS ONE, vol. 8, no. 4, Article ID e62151, 2013.

[44] B. Svobodova, E. Honsova, P. Ronco, V. Tesar, and H. Debiec, "Kidney biopsy is a sensitive tool for retrospective diagnosis of PLA2R-related membranous nephropathy," Nephrology Dialysis Transplantation, vol. 28, no. 7, pp. 1839-1844, 2013.

[45] A. P. Bech, J. M. Hofstra, P. E. Brenchley, and J. F. Wetzels, "Association of anti-PLA $\mathrm{P}_{2} \mathrm{R}$ antibodies with outcomes after immunosuppressive therapy in idiopathic membranous nephropathy," Clinical Journal of the American Society of Nephrology, vol. 9, no. 8, pp. 1386-1392, 2014.

[46] E. Hoxha, I. Thiele, G. Zahner, U. Panzer, S. Harendza, and R. A. K. Stahl, "Phospholipase A2 receptor autoantibodies and clinical outcome in patients with primary membranous nephropathy," Journal of the American Society of Nephrology, vol. 25, no. 6, pp. 1357-1366, 2014.

[47] A. Segarra-Medrano, E. Jatem-Escalante, C. Carnicer-Cáceres et al., "Evolution of antibody titre against the M-type phospholipase A2 receptor and clinical response in idiopathic membranous nephropathy patients treated with tacrolimus," Nefrologia, vol. 34, no. 4, pp. 491-497, 2014.

[48] C. Murtas, M. Bruschi, G. Candiano et al., "Coexistence of different circulating anti-podocyte antibodies in membranous 
nephropathy," Clinical Journal of the American Society of Nephrology, vol. 7, no. 9, pp. 1394-1400, 2012.

[49] G. Mastroianni-Kirsztajn, N. Hornig, and W. Schlumberger, "Autoantibodies in renal diseases-clinical significance and recent developments in serological detection," Frontiers in Immunology, vol. 6, article 221, 2015.

[50] T. Stehlé, V. Audard, P. Ronco, and H. Debiec, "Phospholipase A2 receptor and sarcoidosis-associated membranous nephropathy," Nephrology Dialysis Transplantation, vol. 30, no. 6, pp. 1047-1050, 2015.

[51] A. Khosroshahi, R. Ayalon, L. H. Beck Jr., D. J. Salant, D. B. Bloch, and J. H. Stone, "IgG4-related disease is not associated with antibody to the phospholipase A2 receptor," International Journal of Rheumatology, vol. 2012, Article ID 139409, 6 pages, 2012.

[52] M. A. Hladunewich, S. Troyanov, J. Calafati, and D. C. Cattran, "The natural history of the non-nephrotic membranous nephropathy patient," Clinical Journal of the American Society of Nephrology, vol. 4, no. 9, pp. 1417-1422, 2009.

[53] E. P. McQuarrie, C. M. Stirling, and C. C. Geddes, "Idiopathic membranous nephropathy and nephrotic syndrome: outcome in the era of evidence-based therapy," Nephrology Dialysis Transplantation, vol. 27, no. 1, pp. 235-242, 2012.

[54] Glomerulonephritis Work Group, "KDIGO clinical practice guideline for glomerulonephritis," Kidney International Supplements, vol. 2, no. 2, pp. 1-274, 2012.

[55] D. C. Cattran, Y. Pei, C. M. T. Greenwood, C. Ponticelli, P. Passerini, and E. Honkanen, "Validation of a predictive model of idiopathic membranous nephropathy: its clinical and research implications," Kidney International, vol. 51, no. 3, pp. 901-907, 1997.

[56] J. M. Hofstra and J. F. Wetzels, "Anti-PLA(2)R antibodies in membranous nephropathy: ready for routine clinical practice?" Netherlands Journal of Medicine, vol. 70, no. 3, pp. 109-113, 2012.

[57] R. J. Glassock, "Antiphospholipase A2 receptor autoantibody guided diagnosis and treatment of membranous nephropathy: a new personalized medical approach," Clinical Journal of the American Society of Nephrology, vol. 9, no. 8, pp. 1341-1343, 2014.

[58] L. H. Beck Jr. and D. J. Salant, "Membranous nephropathy: from models to man," Journal of Clinical Investigation, vol. 124, no. 6, pp. 2307-2314, 2014.

[59] E. Hoxha, S. Harendza, H. Pinnschmidt, U. Panzer, and R. A. K. Stahl, "PLA2R antibody levels and clinical outcome in patients with membranous nephropathy and non-nephrotic range proteinuria under treatment with inhibitors of the reninangiotensin system," PLoS ONE, vol. 9, no. 10, Article ID e110681, 2014.

[60] A. Kattah, R. Ayalon, L. H. Beck Jr. et al., "Anti-phospholipase $\mathrm{A}_{2}$ receptor antibodies in recurrent membranous nephropathy," American Journal of Transplantation, vol. 15, no. 5, pp. 13491359, 2015.

[61] S.-L. Hu, D. Wang, W.-J. Gou, Q.-F. Lei, T.-A. Ma, and J.Z. Cheng, "Diagnostic value of phospholipase A2 receptor in idiopathic membranous nephropathy: a systematic review and meta-analysis," Journal of Nephrology, vol. 27, no. 2, pp. 111-116, 2014. 


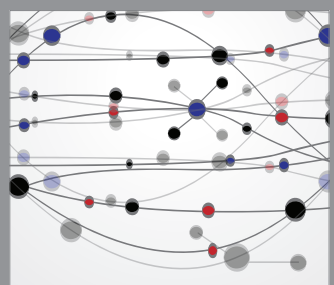

The Scientific World Journal
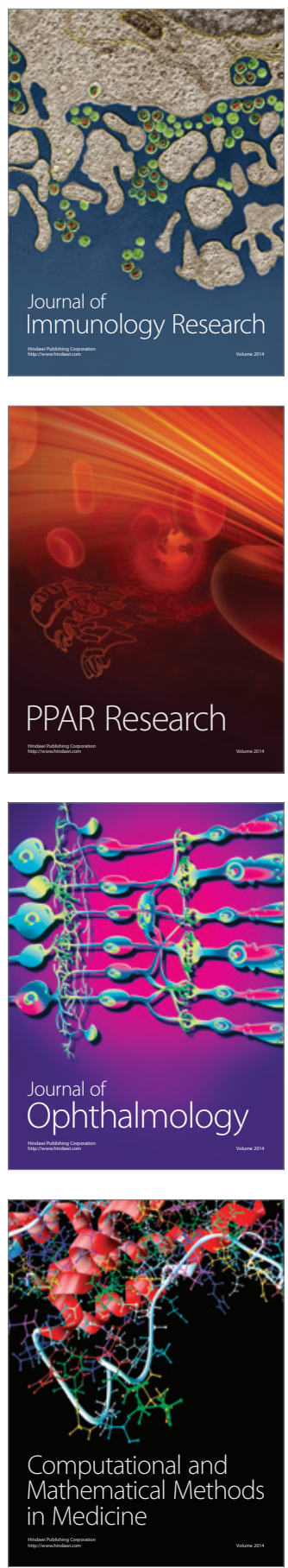

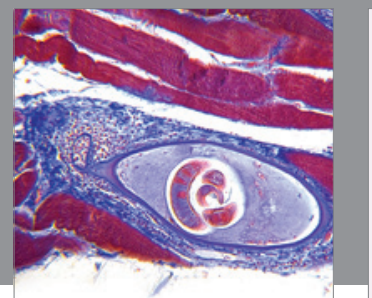

Gastroenterology

Research and Practice
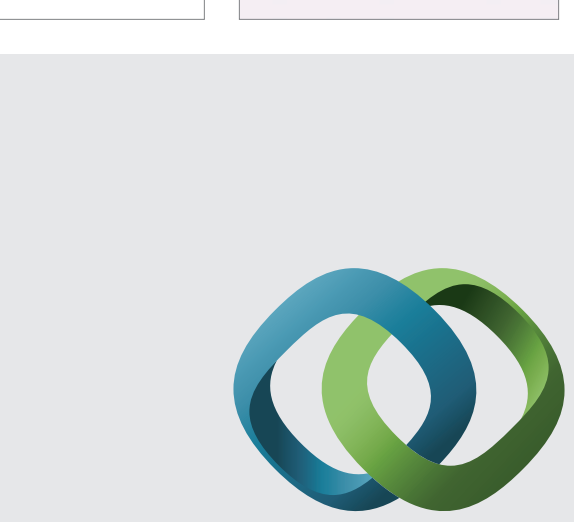

\section{Hindawi}

Submit your manuscripts at

http://www.hindawi.com
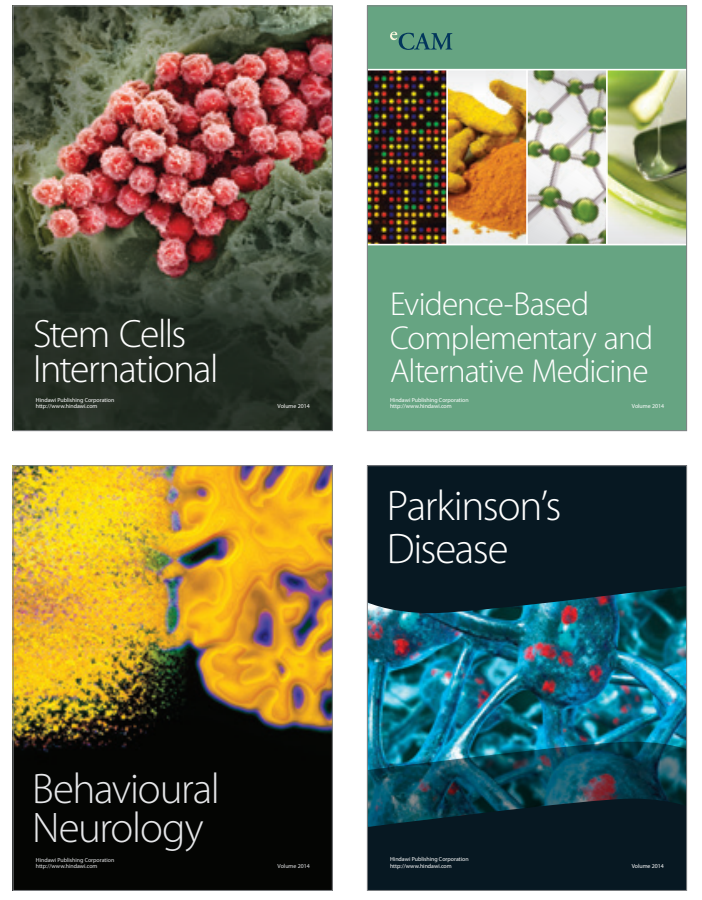
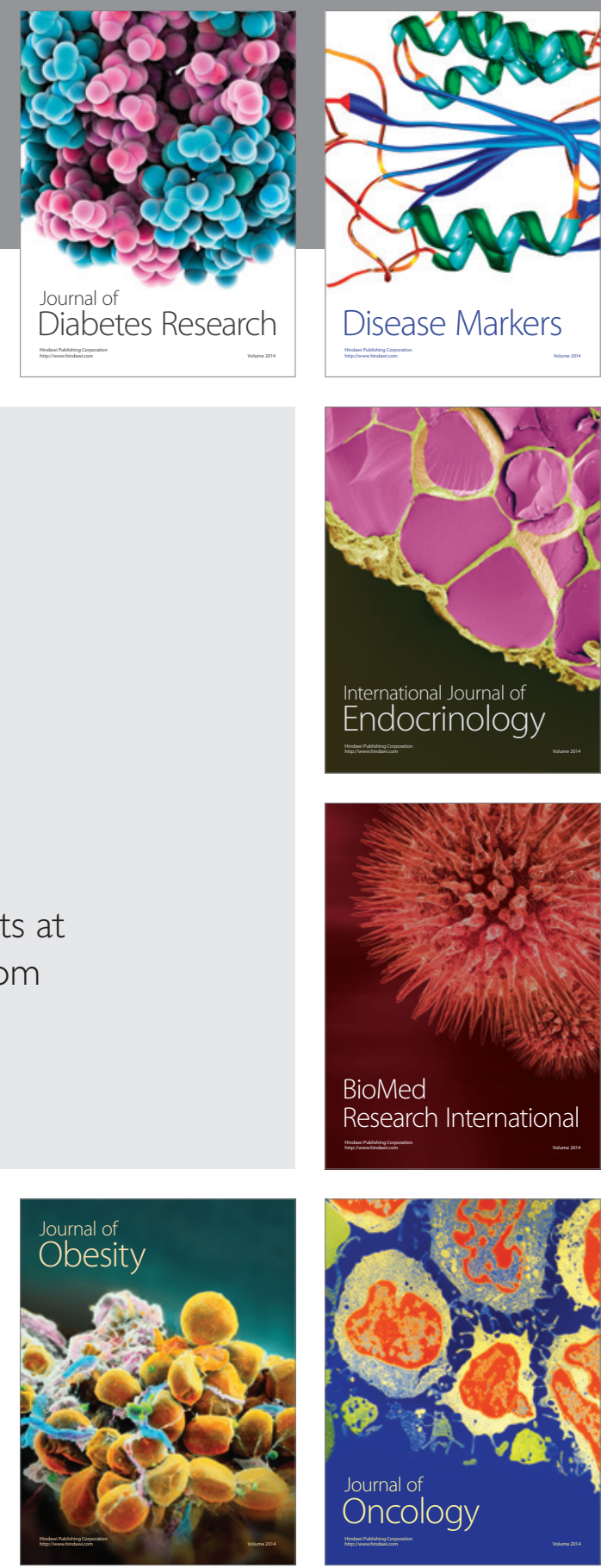

Disease Markers
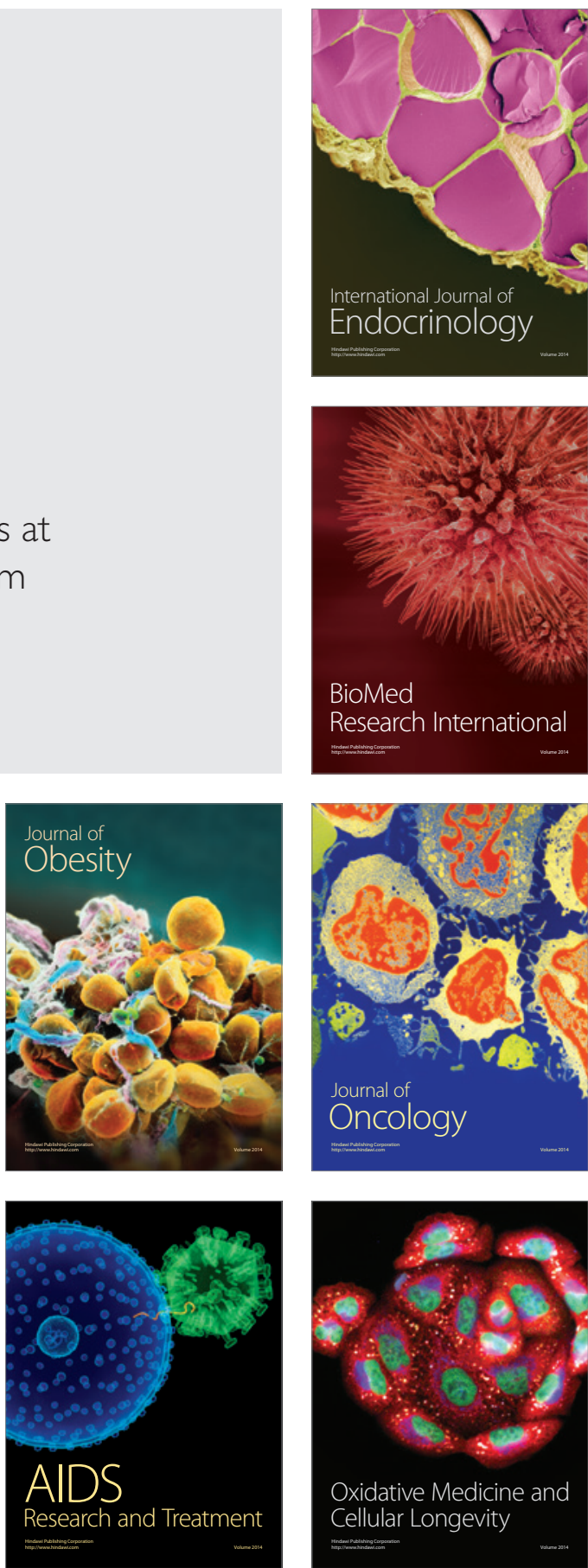